\title{
Does the inflammatory potential of diet affect disease activity in patients with inflammatory bowel disease?
}

\author{
Parvin Mirmiran ${ }^{1,2}$, Nazanin Moslehi ${ }^{1 *}$, Nava Morshedzadeh ${ }^{3 *}$, Nitin Shivappa ${ }^{4,5}$, James R. Hébert ${ }^{4,5}$, \\ Farnaz Farsi ${ }^{6}$ and Naser Ebrahimi Daryani ${ }^{7}$
}

\begin{abstract}
Background: Diet is an important modulator of inflammation, which is associated with inflammatory bowel disease (IBD). In this study, we examined whether the inflammatory properties of diets are associated with disease activity in patients with IBD.

Methods: A cross-sectional study was conducted on 143 IBD patients, including 32 patients with Crohn's disease (CD) and 111 patients with ulcerative colitis (UC). Dietary intakes were assessed by a valid 168-item food frequency questionnaire (FFQ). The inflammatory potential of the diet was assessed by calculating the two scores of Dietary Inflammatory Index $\left(D\|\|^{\oplus}\right)$, and the Empirical Dietary Inflammatory Pattern (EDIP), and CD and UC disease activity were determined by the Crohn's disease activity index (CDAl) and the Mayo score, respectively. Associations of the inflammatory indices as median and as tertiles with disease activity were analyzed using logistic regression in a univariate model and after adjusting for total energy intake (continuous), type of disease (CD and UC) and drug consumption (no drugs, single drug, and multiple drugs).
\end{abstract}

Results: Sixty-four IBD patients (44.8\%) in this study had active disease.The DII ${ }^{\circledast}$ score and the EDIP did not differ significantly between active and inactive patients ( $-1.45 \pm 1.04$ vs. $-1.20 \pm 1.24 ; 0.56 \pm 0.22$ vs. $0.53 \pm 0.28$,

respectively). After adjusting for energy intake, drug use, and IBD type, the odds ( $95 \% \mathrm{Cls}$ ) of active disease among patients in tertile 3 compared to those in tertile 1 were $0.84(0.32-2.17)$ for DII and 1.50 (0.61-3.72) for EDIP; neither of which were statistically significantly different from the rates in tertile 1.

Conclusions: Although point estimates were in the expected direction of increased risk, the inflammatory potential of diet, assessed using DII or EDIP, was not associated with severity of disease in IBD patients. Whether diet-related inflammation affects disease activity in patients with IBD deserves further investigations.

Keywords: Dietary inflammatory index, Empirically derived inflammatory pattern, Inflammatory bowel disease, Disease activity

\footnotetext{
* Correspondence: moslehinazanin@sbmu.ac.ir; moslehinazanin@yahoo.com; nava.morshedzadeh@sbmu.ac.ir; n.morshedzadeh@yahoo.com

${ }^{1}$ Nutrition and Endocrine Research Center, Research Institute for Endocrine Sciences, Shahid Beheshti University of Medical Sciences, Tehran, Iran ${ }^{3}$ Student Research Committee, Department of Clinical Nutrition and Dietetics, Faculty of Nutrition and Food Technology, National Nutrition and Food Technology Research Institute, Shahid Beheshti University of Medical Sciences, Tehran, Iran

Full list of author information is available at the end of the article
}

\begin{abstract}
Background
Inflammatory bowel disease (IBD), characterized by chronic or relapsing inflammation of the gastrointestinal (GI) tract [1], is thought to be a relatively common enteropathy worldwide with the highest annual incidence rate of 24.3 per 100,000 person-years for ulcerative colitis (UC) in Europe and the lowest incidence rate of 5 per 100,000 person-years for Crohn's disease $(\mathrm{CD})$ in Asia and the Middle East [2]. An increasing burden of IBD in Iran suggests that the disease could become an important public health concern in forthcoming years [3].
\end{abstract}

(c) The Author(s). 2019 Open Access This article is distributed under the terms of the Creative Commons Attribution 4.0 International License (http://creativecommons.org/licenses/by/4.0/), which permits unrestricted use, distribution, and 
The etiology of IBD remains unclear but a combination of environmental, genetic, and immune-regulatory factors are thought to be involved [4]. Although the two principal types of IBD can be differentiated by the location of diseases in the gastrointestinal tract, clinical and histological manifestations, complications and prevalence, both types are caused by chronic intestinal inflammation [5].

Food components can affect incidence of IBD and its development at least through modulation of intestinal microbiota, intestinal immune system and inflammation [6]. Studies investigating dietary determinants in the onset of IBD are increasing and some of these suggest meat [7], dairy [8], fiber [9], and vitamin D [10] may influence the risk of developing IBD. Among dietary components, increased attention is being focused on the intake of fish and n-3 fatty acids in the etiology [11] and maintenance of remission of IBD [12] although these studies provided inconsistent findings. Patients with IBD believe that certain foods affect their disease activity [13]. Contrary to the common belief, except for n-3 and fish oil supplementation, the association of other dietary components with disease activity or relapse in IBD patients has not been well investigated [14]. The overall inflammatory properties of the diet may influence disease activity in the inflammatory disease. To assess the properties, dietary inflammatory indices have been developed $[15,16]$. The Dietary Inflammatory Index $\left(\mathrm{DII}^{\circ}\right)$ has been created based on the inflammatory scores of 45 food parameters which are mainly nutrients. Inflammatory properties of the food parameters were obtained from studies published on association between diet and six inflammatory markers through 2010 [15]. The score has been significantly associated with inflammatory markers $[17,18]$ and increased risk of diseases characterized by inflammation [19, 20]. The Empirically Derived Inflammatory Pattern (EDIP) has also been proposed to calculate inflammatory dietary score, based on intakes of food groups. The weighted sum of the 18 food groups is used to calculate EDIP scores. Inflammatory properties of the food groups were determined using reduced rank regression considering CRP, IL- 6 , and TNF- $\alpha$ as response variables, after which their weights were derived using stepwise linear regressions [16]. The ability of the score to predict inflammatory markers of CRP, IL-6, TNF- $\alpha$, and adiponectin has been shown [21]. A higher EDIP score was associated with higher risk of colorectal cancer [22] and metabolic unhealthy phenotype in overweight/ obese adults [23]. Results of a study that examined the association between the DII and risk of UC, suggests an increased risk with higher adherence to the proinflammatory diet [24]. To date, no study has investigated the association of the dietary inflammatory indices and the clinical course of IBD patients. Therefore, the aim of this study was to investigate the associations of inflammatory properties of diet, using the DII and EDIP scores, with disease activity in IBD patients.

\section{Method \\ Study population}

A cross-sectional study was performed on 143 IBD patients including 32 with $\mathrm{CD}$ and 111 with UC. In an effort to reduce the possibility of changes in dietary intake adjustment following IBD diagnosis, only newly diagnosed patients with IBD $<6$ months were selected from among adult IBD patients, aged $\geq 18$ years, referred to Gastroenterology Clinic of Rasool Akram Hospital in Tehran during 2017-2018. The diagnoses of CD and UC were made based on physical, colonoscopic, and histological examinations. Those patients with history of gastrointestinal surgery, other gastrointestinal illnesses, carcinoma, diabetes mellitus, and hyperthyroidism were excluded. In addition, those on special diets (e.g. vegan, Atkins), and pregnant and breastfeeding women were also excluded from the study; CD and UC disease activity was determined by the Crohn's disease activity index (CDAI) and Mayo score, respectively $[25,26]$. Active disease was defined as CDAI $\geq 150$ and Mayo score $<2$ for CD and UC patients, respectively. Ethical committee approval was obtained from the Student Research Committee of Shahid Beheshti University of Medical Sciences.

\section{Anthropometric and demographic parameters}

Data on age, gender, smoking, education, drug consumption, and past medical history were collected using a demographic and medical history questionnaire. Participants were categorized based on education into three groups: < 14 years of formal education, bachelor's degree, master's degree and higher. Drug consumption was categorized into three groups: No drug, a single drug (consumption of aminosalicylic acid compounds (5-ASA) or immune modulators, i.e. azathioprine, prednisolone and methotrexate, each per se, and multiple dugs (combination at least two classes of drugs, including ASA, immune modulator, and anti-tumor necrosis factor (TNF) agents, i.e., Remicade ${ }^{\circledast}$ infliximab and Humira ${ }^{\circledR}$ (adalimumab).

Weight was measured using Seca scales (Germany) to the nearest $0.1 \mathrm{~kg}$ (without shoes and with light clothing) and height was measured to the nearest $1 \mathrm{~cm}$ without shoes. Body mass index (BMI) was calculated as weight in kilograms divided by height in meters squared.

\section{Dietary assessment and DII ${ }^{\circledR}$ and EDIP calculation}

Nutrition information of the patients during the preceding year was assessed using a 168-item food-frequency questionnaire (FFQ) [27]. Frequency of food intake and the amount consumed were recorded and converted to grams. Nutrient composition of the Iranian foods and United States Department of Agriculture (USDA) food 
composition table were used to determine nutrients intakes. The validity of the FFQ was assessed among a subsample of 132 cohort participants against 12 daily dietary recalls collected over a year. Using the FFQ and 12 daily dietary intakes, acceptable correlations were found between nutrients intakes; ranging from 0.24 for vitamin A to 0.70 for thiamin in men and from 0.11 for beta-carotene to 0.60 for fiber in women [27]. Assessing reliability of the FFQ by completing the FFQ twice with an interval of 14 month also showed good correlations ranged from 0.41 for mono-unsaturated fat to 0.79 for protein in men, and from 0.39 for mono-unsaturated fat and 0.74 for saturated fat in women [27].

Inflammatory potential of diet was assessed by calculating the DII ${ }^{\circ}$ and EDIP scores $[15,16]$. To calculate the DII, dietary intakes of 38 food parameters, including energy, carbohydrate, protein, total fat, cholesterol, saturated fat, trans fat, mono-unsaturated fat, polyunsaturated fat, n-3 fatty acid, n- 6 fatty acids, fiber, thiamin, riboflavin, niacin, folic acid, vitamin B6, vitamin $B 12$, vitamin $A$, vitamin $C$, vitamin $D$, vitamin $E$, iron, selenium, magnesium, zinc, beta-carotene, flavan-3-ol, flavones, flavonols, flavonones, anthocyanidins, isoflavones, caffeine, pepper, tea, garlic, and onions were used; to do this, each food parameter was first standardized using the global means and standard deviations (SDs) values; standardized values were then converted to centered percentiles and then multiplied by the overall food parameter specific inflammatory effect scores. The food parameter specific inflammatory scores of each food parameter were summed up to obtain the overall DII score. To control for the effect of total energy intake, DII per $1000 \mathrm{kcal}$ was calculated.

According to the Tabung et al. study, dietary intakes of 15 food groups including tea, coffee, dark yellow vegetables, leafy green vegetables, snacks, fruit juice, pizza, processed meat, red meat, organ meat, other fish, other vegetables, refined grains, high-energy beverages, and tomatoes were used to develop the EDIP. Food items included in each food group are presented in Table 1. First, mean daily intake of each food group was divided by a group specific portion size [28] to determine its intakes based on serving sizes; these values were then multiplied by their specific inflammatory coefficients [16] and summed up and the final values were rescaled by dividing by 1000 to decrease the magnitude of the score and to simplify the interpretation. The greater scores (more positive) indicate more pro-inflammatory diets and the lower scores (more negative) indicate more anti-inflammatory diet.

\section{Statistical analysis}

Characteristics of participants were determined based on disease activity. Comparisons between active and inactive
Table 1 Food groups used to calculate the Empirical Dietary Inflammatory Pattern (EDIP) score

\begin{tabular}{|c|c|}
\hline Food groups & Food items \\
\hline \multicolumn{2}{|l|}{ Pro-inflammatory } \\
\hline Processed meat & Sausages, salami \\
\hline Red meat & Beef, lamb, hamburger patty \\
\hline Organ meat & $\begin{array}{l}\text { Beef / chicken liver, other organ meats of } \\
\text { lamb and beef }\end{array}$ \\
\hline Other fish & Canned tuna, fish other than dark-meat fish \\
\hline Other vegetables & $\begin{array}{l}\text { Celery, mushroom, green pepper, corn, } \\
\text { eggplant, zucchini, cucumber }\end{array}$ \\
\hline Refined grains & $\begin{array}{l}\text { White bread, muffin, bagel or roll breads, } \\
\text { white rice, pasta, biscuits, noodle }\end{array}$ \\
\hline High energy beverages & $\begin{array}{l}\text { Soft drinks, other carbonated beverages with } \\
\text { sugar or fruit punch drinks }\end{array}$ \\
\hline Tomatoes & Fresh Tomato, tomato sauce \\
\hline \multicolumn{2}{|l|}{ Anti-inflammatory } \\
\hline Tea & Dark tea \\
\hline Coffee & Coffee \\
\hline Dark yellow vegetables & Carrots, winter squash \\
\hline Leafy green vegetables & Spinach, lettuce, mixed vegetables \\
\hline Snacks & $\begin{array}{l}\text { Potato chips, corn chips, pufak (extruded } \\
\text { corn snack), popcorn, cracker }\end{array}$ \\
\hline Fruit Juice & Apple, orange, cantaloupe juices \\
\hline Pizza & Pizza \\
\hline
\end{tabular}

disease were made using Student's - $t$ test for continuous variables and Chi-square for categorical variables. Participant characteristics across tertiles of the inflammatory indices were also compared using ANOVA test for continuous variables and Chi-square for categorical variables. Inflammatory indices were analyzed as categorical variables using both median cut-point and tertile cutpoints. Associations between the inflammatory indices and disease activity were analyzed using logistic regression in a univariate model and after adjusting for total energy intake (continuous), type of disease (CD and $\mathrm{UC}$ ) and drug consumption (no drugs, single drug, and multiple drugs). In this study, age, sex, smoking, BMI, education, drug consumption, type of IBD (UC/CD), and energy intakes were selected as potential covariates, and those with significant univariate association with the risk of active disease $(P<0.1)$ were included in the adjusted model. For statistical analyses, SPSS 20 (IBM Corp, Armonk, NY) was used and $P<0.05$ was considered significant.

\section{Results}

Of 143 participants recruited in this study, 64 individuals (44.8\%) had active disease, of whom 43 (67.2\%) had UC. Characteristics of participants based on activity state of disease are presented in Table 2. Age, sex, BMI, number 
Table 2 Characteristics of participants based on disease activity ${ }^{\text {a }}$

\begin{tabular}{|c|c|c|c|c|}
\hline & $\begin{array}{l}\text { Total } \\
(n=143)\end{array}$ & $\begin{array}{l}\text { Inactive } \\
(n=79)\end{array}$ & $\begin{array}{l}\text { Active } \\
(n=64)\end{array}$ & $P$ value \\
\hline Age, years & $38.7 \pm 10.8$ & $37.9 \pm 11.2$ & $39.7 \pm 10.3$ & 0.32 \\
\hline Female, n (\%) & $66(46.2)$ & $38(48.1)$ & $28(43.8)$ & 0.62 \\
\hline $\mathrm{BMl}, \mathrm{kg} / \mathrm{m}^{2}$ & $25.0 \pm 3.03$ & $25.3 \pm 3.21$ & $24.6 \pm 2.78$ & 0.19 \\
\hline Smokers, n (\%) & $22(15.4)$ & $11(13.9)$ & $11(17.2)$ & 0.64 \\
\hline \multicolumn{5}{|l|}{ Education, n (\%) } \\
\hline$<14$ years of formal education & $26(18.2)$ & $18(22.8)$ & $8(12.5)$ & \multirow[t]{3}{*}{0.21} \\
\hline Bachelor's degree & $73(51.0)$ & $36(45.6)$ & $37(57.8)$ & \\
\hline$\geq$ Master's degree & $44(30.8)$ & $25(31.6)$ & $19(29.7)$ & \\
\hline \multicolumn{5}{|l|}{ IBD Type, n (\%) } \\
\hline Crohn's disease & $32(22.4)$ & $11(13.9)$ & $21(32.8)$ & \multirow[t]{2}{*}{0.006} \\
\hline Ulcerative colitis & $111(77.6)$ & $68(86.1)$ & $43(67.2)$ & \\
\hline \multicolumn{5}{|l|}{ Disease activity, Median (min, max) } \\
\hline Crohn's disease activity index & $193(65.0,400)$ & $80.0(65.0,145)$ & $250(155,400)$ & \\
\hline Mayo score for Ulcerative colitis & $1.0(0,11.0)$ & $1.0(0,2.0)$ & $8.0(4.0,11.0)$ & \\
\hline \multicolumn{5}{|l|}{ IBD-related drug consumption, n (\%) } \\
\hline No drugs & $6(4.20)$ & $3(3.80)$ & $3(4.70)$ & \multirow[t]{3}{*}{0.001} \\
\hline Single drugs ${ }^{b}$ & $42(29.4)$ & $33(41.8)$ & $9(14.1)$ & \\
\hline Multiple drugs $^{c}$ & $95(66.4)$ & $43(54.5)$ & $52(81.2)$ & \\
\hline \multicolumn{5}{|l|}{ Dietary intakes } \\
\hline Energy (kcal/d) & $2021 \pm 326$ & $2062 \pm 354$ & $1971 \pm 282$ & 0.09 \\
\hline Carbohydrate (\% of energy) & $62.4 \pm 4.16$ & $62.2 \pm 4.77$ & $62.8 \pm 3.26$ & 0.40 \\
\hline Fat (\% of energy) & $26.2 \pm 3.60$ & $26.4 \pm 4.10$ & $26.0 \pm 2.89$ & 0.51 \\
\hline Protein (\% of energy) & $14.2 \pm 1.38$ & $14.3 \pm 1.56$ & $14.1 \pm 1.11$ & 0.46 \\
\hline Saturated fatty acids ( $\mathrm{g} / \mathrm{d}$ ) & $17.6 \pm 4.57$ & $18.3 \pm 4.94$ & $17.0 \pm 3.95$ & 0.06 \\
\hline Monounsaturated fatty acids (g/d) & $21.5 \pm 4.61$ & $22.0 \pm 5.32$ & $21.0 \pm 3.5$ & 0.23 \\
\hline Polyunsaturated fatty acids (g/d) & $12.7 \pm 2.61$ & $12.8 \pm 2.95$ & $12.6 \pm 2.11$ & 0.65 \\
\hline Grains (g/d) & $497 \pm 167$ & $505 \pm 200$ & $487 \pm 112$ & 0.52 \\
\hline Legumes (g/d) & $13.2 \pm 14.0$ & $13.2 \pm 14.7$ & $13.3 \pm 13.2$ & 0.96 \\
\hline Meats (g/d) & $64.2 \pm 28.8$ & $66.9 \pm 33.8$ & $60.8 \pm 20.9$ & 0.21 \\
\hline Dairy products (g/d) & $233 \pm 155$ & $251 \pm 162$ & $297 \pm 89.3$ & 0.12 \\
\hline Fruits $(\mathrm{g} / \mathrm{d})$ & $293 \pm 78.1$ & $297 \pm 89.3$ & $288 \pm 61.7$ & 0.51 \\
\hline Vegetables (g/d) & $191 \pm 48.7$ & $190 \pm 53.7$ & $193 \pm 42.1$ & 0.72 \\
\hline Fast foods (g/d) & $13.9 \pm 15.1$ & $14.6 \pm 18.4$ & $13.0 \pm 9.67$ & 0.53 \\
\hline \multicolumn{5}{|l|}{ Diet inflammatory scores } \\
\hline DII & $-1.59 \pm 1.24$ & $-1.21 \pm 1.24$ & $-1.45 \pm 1.04$ & 0.23 \\
\hline EDIP & $0.54 \pm 0.25$ & $0.53 \pm 0.28$ & $0.56 \pm 0.22$ & 0.54 \\
\hline
\end{tabular}

${ }^{\mathrm{a}}$ Data are presented as mean \pm SDs unless otherwise stated. ${ }^{\mathrm{b}}$ Consumption of aminosalicylic acid compounds (5-ASA) or immune modulators, i.e. azathioprine, prednisolone and methotrexate, each per se. ${ }^{c}$ Combination at least two classes of drugs, including ASA, immune modulator, and anti-tumor necrosis factor (TNF) agents, i.e., Remicade infliximab and Humira (adalimumab). BMI Body mass index, DIl Dietary inflammatory index inflammatory bowel disease, EDIP Empirically derived inflammatory pattern, IBD Inflammatory bowel disease

of smokers, and education were not significantly different between patients with inactive and active diseases. There were significant differences in drug consumption between patients with inactive and active disease, with consumption of multiple drugs being significantly higher in active $(n=52(81.2 \%)$ vs. inactive patients $(n=43$ (54.5\%), $P=0.001$ ). Intakes of energy, macronutrients, and food groups did not differ significantly according to 
activity of disease. Median and range of DII ${ }^{\circ}$ and EDIP in all participants were $-1.57(-3.66,1.99)$ and $0.54(-$ $0.25,1.31$ ), respectively. Inflammatory diet scores of DII and EDIP did not differ significantly between the two groups.

Characteristics of participants based on tertiles of inflammatory indices are presented in Table 3, except for BMI, which was higher significantly among those in the second and third tertiles of the DII compared to the first, other characteristics did not differ significantly based on tertiles of the scores.

Odds ratios (OR) and 95\% confidence intervals (CI) of having active disease in IBD patients, based on tertiles and median of inflammatory diet scores are shown in Table 4 . No significant association was observed between the DII ${ }^{\circ}$ and disease activity, either using categorization of DII by tertiles or median. Risk of having active disease was higher with higher EDIP scores, tertile or median, but none of these findings reached statistical significance.

\section{Discussion}

In this study, we investigated associations between the inflammatory properties of diets and disease activity in IBD patients. No significant association was observed between either $\mathrm{DII}^{\bullet}$ or EDIP and disease activity in IBD patients.

Inflammation exacerbates symptoms of IBD [1]. There is some evidence suggesting that inflammatory state can be modulated by food parameters [29]. Therefore, dietary intakes may affect progression and severity of IBD via their effects on inflammation [30]. Lacking data on inflammatory markers, we sought to examine the effect of the inflammatory potential of an individual's diet by two dietary scores of DII and EDIP calculated from a Persian FFQ $[15,16]$. The DII, mainly nutrient-based index, was developed by reviewing all data documented by studies on the association of food items, nutrients, and non-nutrient components with six inflammatory markers [15]. The EDIP, a food-group based index, was developed based on a posteriori pattern in an American population, using reduced rank regression [16].

Patients with IBD tend to change their dietary intakes because they believe that certain foods exacerbate their clinical symptom [13]. Despite the belief, limited evidence is available on associations of dietary components and disease activity in these patients. In a prospective study, meat, particularly red meat and processed meat, alcoholic beverages, and protein intakes were associated with increased likelihood of relapse in UC patients [31].

Table 3 Participants characteristics based on tertiles of dietary inflammatory scores

\begin{tabular}{|c|c|c|c|c|}
\hline \multirow[t]{2}{*}{ Variables } & \multicolumn{3}{|c|}{ Inflammatory indexes } & \multirow[t]{2}{*}{$P$-value ${ }^{1}$} \\
\hline & Tertile 1 & Tertile 2 & Tertile 3 & \\
\hline \multicolumn{5}{|l|}{ Dietary Inflammatory Index } \\
\hline Number & 48 & 49 & 46 & - \\
\hline Age, years & $41 \pm 9.87$ & $37.8 \pm 11.3$ & $37.2 \pm 11.0$ & 0.19 \\
\hline Female, n (\%) & $23(47.9)$ & $26(53.1)$ & $17(37.0)$ & 0.28 \\
\hline $\mathrm{BMI}, \mathrm{kg} / \mathrm{m}^{2}$ & $26.8 \pm 2.54$ & $24.5 \pm 2.96$ & $23.6 \pm 2.72$ & $<0.001$ \\
\hline Smokers, n (\%) & $10(20.8)$ & $6(12.2)$ & $6(13)$ & 0.44 \\
\hline \multicolumn{5}{|l|}{ Education, n (\%) } \\
\hline$<14$ years of formal education & $4(8.33)$ & $9(18.4)$ & $13(28.3)$ & \multirow[t]{3}{*}{0.06} \\
\hline Bachelor's degree & $25(52.1)$ & $29(59.2)$ & $19(41.3)$ & \\
\hline$\geq$ Master's degree & 19 (39.6) & $11(22.4)$ & $14(30.4)$ & \\
\hline \multicolumn{5}{|c|}{ Empirically Derived Inflammatory Pattern } \\
\hline Number & 48 & 47 & 48 & - \\
\hline Age, years & $38.2 \pm 10.3$ & $36.9 \pm 11.1$ & $40.9 \pm 10.8$ & 0.18 \\
\hline Female, n (\%) & $23(47.9)$ & $25(53.2)$ & $18(37.5)$ & 0.30 \\
\hline $\mathrm{BMI}, \mathrm{kg} / \mathrm{m}^{2}$ & $24.8 \pm 3.12$ & $24.8 \pm 2.69$ & $25.4 \pm 3.26$ & 0.47 \\
\hline Smokers, n (\%) & $3(6.2)$ & $8(17)$ & $11(22.9)$ & 0.07 \\
\hline \multicolumn{5}{|l|}{ Education, n (\%) } \\
\hline$<14$ years of formal education & $15(31.2)$ & $5(10.6)$ & $6(12.5)$ & \multirow[t]{3}{*}{0.05} \\
\hline Bachelor's degree & $18(37.5)$ & $28(59.6)$ & $27(56.2)$ & \\
\hline$\geq$ Master's degree & $15(31.2)$ & $14(29.8)$ & 15 (31.2) & \\
\hline
\end{tabular}

${ }^{1}$ ANOVA-test and Chi-square test were used for continuous and categorical variables, respectively 
Table 4 Odds ratios $(95 \% \mathrm{Cl})$ of disease activity in IBD patients based on the dietary inflammatory scores ${ }^{\mathrm{a}}$

\begin{tabular}{|c|c|c|c|c|}
\hline Dietary Inflammatory scores & Tertile 1 & Tertile 2 & Tertile 3 & $>$ Median \\
\hline \multicolumn{5}{|l|}{ Dietary Inflammatory Index } \\
\hline Number & 48 & 49 & 46 & \\
\hline Median & -2.31 & -1.56 & 0.01 & -1.57 \\
\hline Min, Max & $-3.66,-1.93$ & $-1.92,-1.09$ & $-1.07,1.99$ & $-3.67,1.99$ \\
\hline Univariate & 1 & $1.33(0.60-2.98)$ & $0.83(0.36-1.89)$ & $0.78(0.40-1.50)$ \\
\hline Adjusted $^{\mathrm{a}}$ & 1 & $1.28(0.52-3.17)$ & $0.84(0.32-2.17)$ & $0.79(0.37-1.68)$ \\
\hline \multicolumn{5}{|c|}{ Empirically Derived Inflammatory Pattern } \\
\hline Number & 48 & 47 & 48 & \\
\hline Median & 0.3 & 0.53 & 0.8 & 0.54 \\
\hline Min, Max & $-0.25,0.44$ & $0.45,0.66$ & $0.67,1.31$ & $-0.25,1.31$ \\
\hline Univariate & 1 & $1.34(0.6-3.03)$ & $1.40(0.62-3.15)$ & $1.61(0.83-3.14)$ \\
\hline Adjusted $^{a}$ & 1 & $1.57(0.65-3.81)$ & $1.50(0.61-3.72)$ & $1.72(0.83-3.59)$ \\
\hline
\end{tabular}

${ }^{a}$ Adjusted for total energy intake (continuous), type of disease (CD /UC) and drug consumption (no drugs, single drug, and multiple drugs)

A cross-sectional study of 103 adults with IBD reported a $79 \%$ lower risk of active disease in the highest quartiles of legumes and potato intakes versus the lowest [32]; these studies could not find any significant associations between cereals, fruits and vegetables, dairy products, fish [31, 32], carbohydrate, fat, fiber intakes and disease activity [31]. Considering the anti-inflammatory properties of fish and $n-3$ fatty acids, the effects of n-3 fatty acids on disease activity have been examined in clinical trials but no beneficial effects were reported [12, 33].

Despite point estimates trending in the expected direction, findings of our study were not consistent with the hypothesis that diet-induced inflammation increases disease activity in IBD patients. The combination of its small sample size and potential mask by complex factors involving the pathogenesis of IBD may have obscured a relationship. Slight variations in the ranges of these dietary indices across participants may also result in these null findings. In the current study, 83\% of the population consumed the anti-inflammatory diet based on the DII, suggesting that participants of this study may have relatively healthy dietary intakes. In addition, it is probable that inflammatory indices modulate inflammation in the patients but could not affect the clinical course, an observation that is reported for $\mathrm{n}-3$ supplementation. Clinical trials suggest that $\mathrm{n}-3$ fatty acid supplementation in IBD patients reduces inflammation and lessens the need for steroid therapy but does not maintain remission [34].

The association between inflammatory dietary scores and IBD has been investigated in one other study, also conducted in Iran, in which DII was computed using 27 food parameters, and results showed that greater adherence to the pro-inflammatory diet was associated with increased risk of UC; a comparison of DII between cases and controls clearly shows that healthy controls had higher adherence to anti-inflammatory diet than patients with UC [24].

To the best our knowledge, this is the first investigation of association between dietary inflammatory indices and disease activity in IBD patients. Using two dietary inflammatory scores with different concept and design is the main strength of this study; some limitations, however, also should be noted. First, the cross-sectional design of the study does not allow for control of reverse causation; i.e., changes in dietary intakes in active patients are possible. Second, these two indices had not been validated using inflammatory markers in the general Iranian population. Previous studies using different inflammatory markers showed validity of scores on predicting the inflammatory markers $[17,18,21]$. In Iran, a case-control study on gastric cancer showed the validity of the DII using 4 inflammatory markers [35] but their validity in general population of Iran has not been investigated, although it has been suggested that these scores can be adapted in different populations $[15,16]$. Third, because of unavailability of information on intakes of alcohol, ginger, saffron, turmeric, thyme/oregano, rosemary, and eugenol only 38 out of 45 food parameters were used to calculate the DII score. In addition, drinking low-energy beverages, beer, and wine were not included to construct EDIP; however, excluding these items does not seem to change the inflammatory scores because of their low consumption in these populations. Fourth, FFQs are well known to be biased by a number of factors [36, 37]. This would be more of a problem in a study in which people are aware of their diagnosis, which is related to diet. This cohort of patients may adjust their diet following the IBD diagnosis and knowledge of the effect of diet on the gut, thus may introduce bias into the measure. Fifth, this study is limited by its 
small sample size; the fact that results were trending in the right direction highlights this concern; and lastly, CDAI and Mayo scores are the most frequently used tools to assess disease activity indirectly in patients with IBD but they may not be as accurate as direct methods of assessing intestinal inflammatory activity. Although direct methods including histopathological and endoscopical examinations provide accurate evidence of intestinal inflammatory activity, they are time consuming, invasive, and expensive, which limit their applicability in routine use in clinical settings [38].

\section{Conclusions}

Overall, in this cohort of IBD patients, the inflammatory potential of diet assessed by the DII and EDIP was not associated with severity of disease. Identification of food components in relation to disease activity in patients with IBD can lead to better management of the disease. In this regard, the hypothesis that diet induced inflammation can affect disease activity in patients with IBD deserves further investigation.

\footnotetext{
Abbreviations

5-ASA: AminosalicylicAcid; APC: Antigen-Presenting Cells; CD: Crohn'sDisease: CDAl: Crohn'sDisease Activity Index; CHI: Connecting Health Innovations; Cl: Confidence Intervals; CRP: C-Reactive Protein; DII : Dietary Inflammatory Index; EDIP: Empirically Derived Inflammatory Pattern; FFQ: Food Frequency Questionnaire; GI: Gastrointestinal; IBD: Inflammatory bowel disease; IL1ß: Interleukin-1 $\beta$; IL-6: Interleukin-6; OR: Odds Ratios; Thcells: T helper Cells; TNF-alpha: Tumor Necrosis Factor-alpha; UC: Ulcerative Colitis; USDA: United States Department of Agriculture
}

\section{Acknowledgements}

This study is related to the project NO.1396/56463 from Student Research Committee, Shahid Beheshti University of Medical Sciences, and Tehran, Iran. The authors wish to acknowledge MS. Nilofar Shiva for critical editing of English grammar and syntax of the manuscript.

\section{Authors' contributions}

NM, NM and PM designed the research; NM, FF and NED contributed to acquisition of data. NM, NM, NS and JRH performed statistical analyses and interpretation of data. NM and NM wrote the manuscript. NM, NM, NS and JR.H contributed to critical revision of the manuscript. Each author has participated sufficiently in the work to take public responsibility for appropriate portions of the content. All authors read and approved the final manuscript.

\section{Funding}

This study had no funding.

\section{Availability of data and materials}

Data that support the findings of this study are available from the corresponding author upon reasonable request.

\section{Ethics approval and consent to participate}

The protocol was approved by the ethics committee of the student research committee, Shahid Beheshti University of Medical Sciences, and Tehran, Iran. Prior to data collection, the purpose of the study was explained to the participants and their informed consent was recorded.

\section{Consent for publication}

Not applicable.

\section{Competing interests}

The Dietary Inflammatory Index $\left(\mathrm{D} \|^{\oplus}\right)$ is a registered trademark of the University of South Carolina. Dr. James R. Hébert owns controlling interest in Connecting Health Innovations LLC (CHI), a company planning to license the right to his invention of the DII ${ }^{\otimes}$ from the University of South Carolina in order to develop computer and smart phone applications for patient counseling and dietary intervention in clinical settings. Dr. Nitin Shivappa is an employee of $\mathrm{CHI}$. These activities have no direct bearing on the use of the $\mathrm{D} \|^{\oplus}$ as a research tool.

The other authors declare that they have no competing interests.

\section{Author details}

${ }^{1}$ Nutrition and Endocrine Research Center, Research Institute for Endocrine Sciences, Shahid Beheshti University of Medical Sciences, Tehran, Iran. ${ }^{2}$ Department of Clinical Nutrition and Dietetics, Faculty of Nutrition and Food Technology, National Nutrition and Food Technology Research Institute, Shahid Beheshti University of Medical Sciences, Tehran, Iran. ${ }^{3}$ Student Research Committee, Department of Clinical Nutrition and Dietetics, Faculty of Nutrition and Food Technology, National Nutrition and Food Technology Research Institute, Shahid Beheshti University of Medical Sciences, Tehran, Iran. ${ }^{4}$ Cancer Prevention and Control Program, University of South Carolina, Columbia, SC, USA. ${ }^{5}$ Department of Epidemiology and Biostatistics, Arnold School of Public Health, University of South Carolina, Columbia, SC, USA. ${ }^{6}$ Colorectal Research Center, Iran University of Medical Sciences, Tehran, Iran. ${ }^{7}$ Department of Gastroenterology, Imam Khomeini Hospital, Tehran University of Medical Sciences, Tehran, Iran.

Received: 15 April 2019 Accepted: 2 October 2019

Published online: 04 November 2019

\section{References}

1. Park JH, Peyrin-Biroulet L, Eisenhut M, Shin JI. IBD immunopathogenesis: a comprehensive review of inflammatory molecules. Autoimmun Rev. 2017; 16:416-26.

2. Ye Y, Pang Z, Chen W, Ju S, Zhou C. The epidemiology and risk factors of inflammatory bowel disease. Int J Clin Exp Med. 2015;8:22529-42.

3. Malekzadeh MM, Vahedi H, Gohari K, Mehdipour P, Sepanlou SG, Ebrahimi Daryani N, et al. Emerging epidemic of inflammatory bowel disease in a middle income country: a nation-wide study from Iran. Arch Iran Med. 2016;19:2-15.

4. Zhang M, Sun $K$, Wu $Y$, Yang $Y$, Tso P, Wu Z. Interactions between intestinal microbiota and host immune response in inflammatory bowel disease. Front Immunol. 2017;8:942.

5. Kim DH, Cheon JH. Pathogenesis of inflammatory bowel disease and recent advances in biologic therapies. Immune Network. 2017;17:25-40.

6. Witkowski M, Witkowski M, Gagliani N, Huber S. Recipe for IBD: can we use food to control inflammatory bowel disease? Semin Immunopathol. 2018; 40:145-56.

7. Ge J, Han TJ, Liu J, Li JS, Zhang XH, Wang Y, et al. Meat intake and risk of inflammatory bowel disease: a meta-analysis. Turk J Gastroenterol. 2015;26:492-7.

8. Opstelten JL, Leenders M, Dik VK, Chan SS, van Schaik FD, Khaw KT, et al. Dairy products, dietary calcium, and risk of inflammatory bowel disease: results from a European prospective cohort investigation. Inflamm Bowel Dis. 2016:22:1403-11.

9. Ananthakrishnan AN, Khalili $H$, Konijeti GG, Higuchi LM, de Silva P, Korzenik JR, et al. A prospective study of long-term intake of dietary fiber and risk of Crohn's disease and ulcerative colitis. Gastroenterology. 2013;145:970-7

10. Mouli VP, Ananthakrishnan AN. Review article: vitamin D and inflammatory bowel diseases. Aliment Pharmacol Ther. 2014;39:125-36.

11. Mozaffari H, Daneshzad E, Larijani B, Bellissimo N, Azadbakht L. Dietary intake of fish, n-3 polyunsaturated fatty acids, and risk of inflammatory bowel disease: a systematic review and meta-analysis of observational studies. Eur J Nutr. 2019. https://doi.org/10.1007/s00394-019-01901-0.

12. Turner D, Shah PS, Steinhart AH, Zlotkin S, Griffiths AM. Maintenance of remission in inflammatory bowel disease using omega-3 fatty acids (fish oil): a systematic review and meta-analyses. Inflamm Bowel Dis. 2011;17:336-45.

13. Jowett SL, Seal CJ, Phillips E, Gregory W, Barton JR, Welfare MR. Dietary beliefs of people with ulcerative colitis and their effect on relapse and nutrient intake. Clin Nutr. 2004;23:161-70. 
14. Richman E, Rhodes JM. Review article: evidence-based dietary advice for patients with inflammatory bowel disease. Aliment Pharmacol Ther. 2013;38: $1156-71$.

15. Shivappa N, Steck SE, Hurley TG, Hussey JR, Hébert JR. Designing and developing a literature-derived, population-based dietary inflammatory index. Public Health Nutr. 2014;17:1689-96.

16. Tabung FK, Smith-Warner SA, Chavarro JE, Wu K, Fuchs CS, Hu FB, et al. Development and validation of an empirical dietary inflammatory index-3. J Nutr. 2016;146:1560-70.

17. Cavicchia PP, Steck SE, Hurley TG, Hussey JR, Ma Y, Ockene IS, et al. A new dietary inflammatory index predicts interval changes in serum highsensitivity C-reactive protein. J Nutr. 2009;139:2365-72.

18. Shivappa N, Hebert JR, Marcos A, Diaz LE, Gomez S, Nova E, et al. Association between dietary inflammatory index and inflammatory markers in the HELENA study. Mol Nutr Food Res. 2017;61.

19. Fowler ME, Akinyemiju TF. Meta-analysis of the association between dietary inflammatory index (DII) and cancer outcomes. Int J Cancer. 2017;141:2215-27.

20. Shivappa N, Godos J, Hebert JR, Wirth MD, Piuri G, Speciani AF, et al. Dietary inflammatory index and cardiovascular risk and mortality-a meta-analysis. Nutrients. 2018:10.

21. Tabung FK, Giovannucci EL, Giulianini F, Liang L, Chandler PD, Balasubramanian R, et al. An Empirical Dietary Inflammatory Pattern Score Is Associated with Circulating Inflammatory Biomarkers in a Multi-Ethnic Population of Postmenopausal Women in the United States. J Nutr. 2018; 148(5):771-80.

22. Tabung FK, Liu L, Wang W, Fung TT, Wu K, Smith-Warner SA, et al. Association of Dietary Inflammatory Potential with Colorectal Cancer Risk in men and women. JAMA Oncol. 2018;4:366-73.

23. Soltani S, Moslehi N, Hosseini-Esfahani F, Vafa M. The association between empirical dietary inflammatory pattern and metabolic phenotypes in overweight/obese adults. Int J Endocrinol Metab. 2018;16:e60048.

24. Shivappa N, Hébert JR, Rashvand S, Rashidkhani B, Hekmatdoost A. Inflammatory potential of diet and risk of ulcerative colitis in a case-control study from Iran. Nutr Cancer. 2016;68:404-9.

25. Lewis JD, Chuai S, Nessel L, Lichtenstein GR, Aberra FN, Ellenberg JH. Use of the noninvasive components of the Mayo score to assess clinical response in ulcerative colitis. Inflamm Bowel Dis. 2008;14:1660-6.

26. Jørgensen LG, Fredholm L, Petersen PH, Hey H, Munkholm P, Brandslund I. How accurate are clinical activity indices for scoring of disease activity in inflammatory bowel disease (IBD)? Clin Chem Lab Med. 2005;43:403-11.

27. Mirmiran P, Esfahani FH, Mehrabi Y, Hedayati M, Azizi F. Reliability and relative validity of an FFQ for nutrients in the Tehran lipid and glucose study. Public Health Nutr. 2010;13:654-62.

28. Hu FB, Rimm E, Smith-Warner SA, Feskanich D, Stampfer MJ, Ascherio A, et al. Reproducibility and validity of dietary patterns assessed with a foodfrequency questionnaire. Am J Clin Nutr. 1999;69:243-9.

29. Minihane AM, Vinoy S, Russell WR, Baka A, Roche HM, Tuohy KM, et al. Lowgrade inflammation, diet composition and health: current research evidence and its translation. Br J Nutr. 2015;114:999-1012.

30. Lee D, Albenberg L, Compher C, Baldassano R, Piccoli D, Lewis JD, et al. Diet in the pathogenesis and treatment of inflammatory BoweláDiseases. Gastroenterology. 2015;148:1087-106.

31. Jowett SL, Seal CJ, Pearce MS, Phillips E, Gregory W, Barton JR, et al. Influence of dietary factors on the clinical course of ulcerative colitis: a prospective cohort study. Gut. 2004;53:1479-84.

32. Tasson L, Canova C, Vettorato MG, Savarino E, Zanotti R. Influence of diet on the course of inflammatory bowel disease. Dig Dis Sci. 2017;62:2087-94.

33. Lev-Tzion R, Griffiths AM, Leder O, Turner D. Omega 3 fatty acids (fish oil) for maintenance of remission in Crohn's disease. Cochrane Database Syst Rev. 2014:CD006320. https://doi.org/10.1002/14651858.CD006320.

34. Scaioli E, Liverani $E$, Belluzzi A. The imbalance between n-6/n-3 polyunsaturated fatty acids and inflammatory bowel disease: a comprehensive review and future therapeutic perspectives. Int J Mol Sci. 2017;18.

35. Vahid F, Shivappa N, Faghfoori Z, Khodabakhshi A, Zayeri F, Hebert JR, et al. Validation of a dietary inflammatory index (DII) and association with risk of gastric Cancer: a case-control study. Asian Pac J Cancer Prev. 2018;19:1471-7.

36. Hebert JR, Ma Y, Clemow L, Ockene IS, Saperia G, Stanek EJ 3rd, et al. Gender differences in social desirability and social approval bias in dietary self-report. Am J Epidemiol. 1997;146:1046-55.
37. Hebert JR, Hurley TG, Peterson KE, Resnicow K, Thompson FE, Yaroch AL, et al. Social desirability trait influences on self-reported dietary measures among diverse participants in a multicenter multiple risk factor trial. J Nutr. 2008;138:226S-34S.

38. Vilela EG, Torres HO, Martins FP, Ferrari Mde L, Andrade MM, Cunha AS. Evaluation of inflammatory activity in Crohn's disease and ulcerative colitis. World J Gastroenterol. 2012;18:872-81.

\section{Publisher's Note}

Springer Nature remains neutral with regard to jurisdictional claims in published maps and institutional affiliations.
Ready to submit your research? Choose BMC and benefit from:

- fast, convenient online submission

- thorough peer review by experienced researchers in your field

- rapid publication on acceptance

- support for research data, including large and complex data types

- gold Open Access which fosters wider collaboration and increased citations

- maximum visibility for your research: over $100 \mathrm{M}$ website views per year

At BMC, research is always in progress.

Learn more biomedcentral.com/submissions 